an accurate history of continuous dribbling is appreciated, it can be very difficult to diagnose with certainty otherwise.

Diagnostic imaging is often unhelpful, and this may be the cause of great delay ${ }^{2-4}$; on average, girls have 10 imaging tests to make the diagnosis. ${ }^{2}$ The dysplastic kidney can often be identified by ultrasound, ${ }^{2-4}$ or on dimercapto succinic acid scanning. ${ }^{1-4}$ However, the course of the distal ureter is difficult to follow with ultrasound, and such poorly functioning moieties excrete little radioisotope or contrast into the ureter, so intravenous urography or MAG-3 renography are seldom helpful. ${ }^{2-4}$ Micturating urography has no role. ${ }^{3}$ Though an ectopic orifice may be visible, ${ }^{23}$ often they are not,,$^{2-4}$ as in our case. There is a clear advantage in confirming the diagnosis before surgery is undertaken.

1 Goonasekera CD, Shah V, Wade AM, Barratt TM, Dillon MJ. 15-year follow-up of renin and blood pressure in reflux nephropathy. Lancet 1996;347:640-3.

2 Borer JG, Bauer SB, Peters CA, Diamond DA, Decter RM, Shapiro E. A single-system ectopic ureter draining an ectopic dysplastic kidney: delayed diagnosis in the young female with continuous urinary incontinence. $\mathrm{Br} \mathcal{F}$ Urol 1998;81:474-8.

3 Carrico C, Lebowitz RL. Incontinence due to an infrasphincteric ectopic ureter: why the delay in diagnosis and what the radiologist can do about it Pediatr Radiol 1998;28:942-9.

4 Pattaras JG, Rushton HG, Majd M. The role of 99 mtechnetium dimercapto-succinic acid renal scans in the evaluation of occult ectopic ureters in girls with paradoxical of occult ectopic ureters in girls
incontinence. F Urol 1999;162:821-5.

5 Mackie GG, Stevens FD. Duplex kidneys: a correlation of renal dysplasia with position of the ureteral orifice. $\mathcal{F}$ Urol 1975;114:274-80

\title{
Zinc deficiency
}

Zinc is an essential micronutrient, and zinc deficiency affects gene expression, protein synthesis, and immune function as well as taste and appetite. Studies in developing countries on the effect of zinc supplementation have given conflicting results. Now a study in rural Ethiopia (Melaka Umeta and colleagues Lancet 2000;355:2021-6) has shown that zinc supplementation improved growth in infants.

The study included 100 apparently healthy breastfed 6-12 month old infants who were stunted (length for age $Z$ score $<-2$ ) and 100 infants matched for age and sex who were not stunted. They were randomly assigned to zinc sulphate $10 \mathrm{mg}$ or placebo daily for six days a week for six months. Over the six months the mean growth in length of stunted infants was $7.0 \mathrm{~cm}$ with zinc and $2.8 \mathrm{~cm}$ with placebo. Growth of the non-stunted group was $6.6 \mathrm{~cm}$ (zinc) $v 5.0 \mathrm{~cm}$ (placebo). The corresponding increases in weight were: stunted infants $1.73 \mathrm{~kg}$ (zinc) $v 0.95 \mathrm{~kg}$ (placebo); non-stunted $1.19 \mathrm{~kg} v 1.02 \mathrm{~kg}$. Zinc supplementation reduced the incidences of anorexia, fever, diarrhoea, vomiting, and cough in stunted infants. At the end of the study, serum and hair zinc concentrations were lower in non-supplemented stunted infants than in non-supplemented non-stunted infants (they were not measured at the beginning of the study) and zinc concentrations in supplemented stunted infants correlated with growth in length.

Zinc supplementation may improve growth in some children in developing countries. Whether the effect is a direct effect of zinc on growth or a result of improved appetite, fewer infections, and less diarrhoea is uncertain.

ARCHIVIST 